\title{
A review of recent advances in the management of breast cancer related pain
}

\author{
Jennifer Zocca*,1, Ali Valimahomed ${ }^{2}$, James $\mathrm{Yu}^{3}$ \& Amitabh Gulati ${ }^{4}$ \\ ${ }^{1}$ Department of Pain Management, Maiden Lane Medical, 18 East, 41st Street, LLC, New York, NY, 10017, USA \\ ${ }^{2}$ Department of Pain Medicine \& Anesthesia, Brigham \& Women's Hospital: Boston Hospital \& Medical Center, 75 Francis Street, \\ Boston, MA, 02115, USA \\ ${ }^{3}$ Touro College of Osteopathic Medicine, 230 West, 125th Street, New York, NY, 10027, USA \\ ${ }^{4}$ Department of Anesthesiology \& Critical Care, Memorial Sloan Kettering Cancer Center, 1275 York Avenue, New York, NY \\ 10065, USA \\ *Author for correspondence: Tel.: +1 908578 0214; Fax: +1 212532 43662; Jennifer.zocca@gmail.com
}

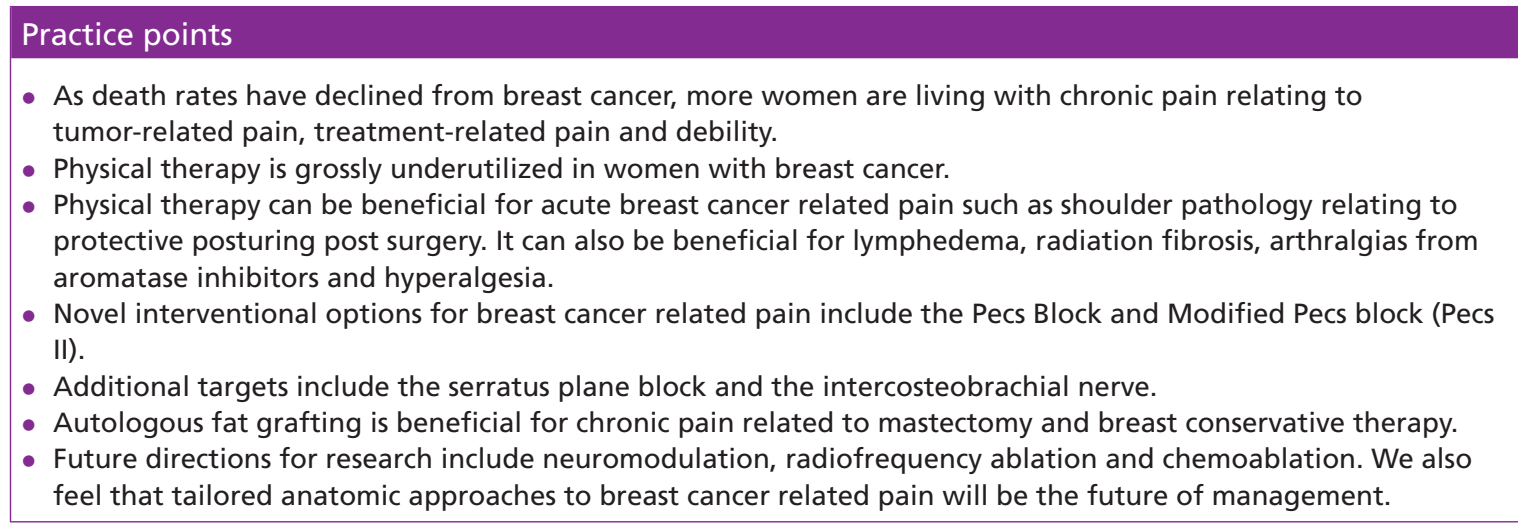

The incidence of breast cancer has stabilized over the past 10 years, while death rates have declined. Thus, many women are living with long-term effects of breast cancer, including pain syndromes relating to breast cancer. As our understanding of these types of pain syndromes improves, delivery of care to this population becomes paramount. In this review, we discuss advances in rehabilitation and interventional pain management to improve pain and symptom management. Appropriate use of physical therapy may significantly improve a patient's functional status, while fascial plane blocks can lead to pain relief which may last for months. Targeted therapies for pain relief may result in better quality of life for individuals suffering from breast cancer related pain.

First draft submitted: 17 January 2018; Accepted for publication: 19 April 2018; Published online: 16 May 2018

Keywords: breast cancer • breast physical therapy • cancer pain • Pecs block • serratus plane block

\section{Background}

Chronic pain following breast cancer treatment is commonly observed and often undertreated. There were an estimated 246,660 new cases of breast cancer in 2016, comprising $14.6 \%$ of all new cancer cases [1]. The incidence of breast cancer has remained stable over the past 10 years, while rates of death have decreased roughly $1.9 \%$ per year between 2004 and 2013. Therefore, quality of life of breast cancer survivors is an important consideration, as there are many women living with the long-term effects of this disease [2].

Breast cancer-related pain can be divided into three distinct categories: tumor-related pain, treatment-related pain and debility or pain unrelated to cancer, and can occur as acute, subacute or chronic pain. Tumor-related pain usually occurs during active treatment and in advanced disease stages. Treatment-related pain can present acutely and become chronic during treatments consisting of chemotherapy, radiation or hormonal therapy [3]. Subacute breast cancer-related pain is most often associated with arm and shoulder pain following breast cancer surgery [4].

Future Medicine 
However, surgical pain syndromes can vary in temporal presentations and may overlap with other treatmentrelated pain. Therefore, it may also be helpful to consider pain syndromes with an organ systems approach. The systems primarily affected in breast cancer-related pain include the musculoskeletal, neurologic, lymphatic and integumentary systems.

Therapeutic options for breast cancer-related pain are predominantly in response to development of pain, although strategies attempting to prevent development of chronic pain are under active investigation. Physical therapy is underutilized, with one study suggesting up to $90 \%$ of patients would benefit from some form of physical therapy, while only 30\% received it [5]. Pharmacologic management of pain includes use of opioids, antiepileptics, sodium channel blockers and antidepressants. Interventional therapies are widely varied and many are currently under investigation. However, it is often necessary to utilize multiple modalities of treatment to achieve adequate pain control of women with breast cancer-related pain.

\section{Advances in rehabilitation for breast cancer related pain}

Exercise has been shown to reduce chronic cancer pain related to treatment [6]. Physical therapy is the use of physical methods such as exercise, stretching, massage and modalities to maximize function, improve quality of life and treat pathology. Physical therapy typically involves a stepwise progression of gentle range of motion and stretching exercises, followed by strengthening and conditioning exercise when acute symptoms subside. Therapy should also include postural/ergonomic training as well as a home exercise program for maintenance [7]. As a treatment modality, physical therapy is grossly underutilized in the breast cancer population [5].

In the acute phase, mastectomy and axillary dissection results in local inflammation, tissue damage, nerve dysfunction and focal edema, all of which may lead to pain. Post-surgical pain can lead to learned disuse of the arm on the affected breast and protective posturing, which results in shortening of the muscles of the anterior chest wall, straining/stretching of the upper neck and back muscles and weakness of the rotator cuff muscles, potentiating poor biomechanics and painful pathology of the shoulder [8-11]. Physical therapy has been shown to significantly decrease pain in breast cancer patients with common painful shoulder disorders [12-14]. Treatment is typically focused on the upper extremity; specifically maintaining shoulder range of motion (forward flexion, abduction, internal rotation and external rotation), rotator cuff and upper back strengthening, pectoral stretching, scapular stabilization, myofascial release/soft tissue mobilization, neuromuscular re-education and home exercise program [15]. Therapy with skin desensitization may also help to reduce post-operative hyperalgesia and neuromas [16-20].

Breast reconstruction with surgical implants following mastectomy may lead to pain and dysfunction due to surgical trauma, stretching secondary to tissue expander use, muscle spasms and fibrosis [21]. In breast cancer patients with painful post-mastectomy adhesions, radiation-induced fibrosis and axillary web syndrome, physical therapy with an emphasis on scar tissue mobilization may be beneficial [22]. Physical therapy addressing core strength is especially important in those who have undergone breast reconstruction with an autologous transverse rectus abdominis myocutaneous flap. Harvesting from the transverse rectus abdominis may result in a core weakness and a subsequent increase in the incidence of lower back pain, especially in those with pre-existing low back pain [23,24].

The use of aromatase inhibitors (e.g., anastrozole) in post-menopausal women with hormone receptor positive breast cancer is now a routine because it significantly reduces the rate of cancer recurrence and decreases mortality. Unfortunately, myalgias and arthralgias are a common side effect of this medication class, leading to medication noncompliance $[25,26]$. This patient population seems to respond well to conservative treatment. Aerobic exercise, yoga and physical therapy have all been shown to significantly decrease pain in patients with aromatase-inhibitor induced arthralgias and myalgias [26-29].

Lymphedema is commonly seen in breast cancer patients and over time it may contribute to both primary and secondary pain syndromes. Increased limb weight from lymphedema may result in subsequent abnormal biomechanics, leading to pathology, such as rotator cuff tendinopathy, shoulder impingement and adhesive capsulitis $[30,31]$. Conservative treatment of lymphedema in breast cancer patients involves complete decongestive lymphatic therapy with an 'intense phase' manual lymphatic drainage, compression dressings/gloves, physical therapy to maximize functional ability and restore lymphatic circulation and a 'self-management phase' [32]. A specialized physical therapist trained in the lymphedema management is critical to the 'intense phase' of treatment, which involves manual lymphatic drainage, compression dressings/gloves as well as active physical therapy to maximize functional ability and restore lymphatic circulation [32].

There are not universally accepted guidelines on when to initiate physical therapy; it is typically started shortly after the completion of breast cancer treatment. Of note, studies show that initiation of physical therapy early 
in the first week postoperatively (status post mastectomy or lymphadenectomy) is associated with an increased risk of wound drainage and seroma formation. Therefore, it is recommended to introduce physical therapy in a graded fashion; waiting until a few days to a week postoperatively to start low intensity exercises (i.e., PROM, AROM and light stretching exercises such as pendulums, wall climbs and pulley exercises), before advancing to more high-intensity resisted exercises [33]. The literature is not consistent with regard to the frequency and duration of physical therapy. Most treatment ranges from one- to three-times per week for a total of 1-3 months and will vary based on the individual needs of the patient [34].

Compliance with physical therapy is often the mainstay of treatment for a long-term return to painless range of motion and strength in patients who are affected by chronic pain relating to breast cancer. Physical therapy should be considered as first line or adjuvant treatment for many painful pathologies in breast cancer. Most importantly, specialized therapies for specific sequelae (rotator cuff tendinopathy, shoulder impingement syndrome, adhesive capsulitis, myofascial pain syndrome, scapular dyskinesias, lymphedema) of post mastectomy pain syndrome are available and need to be considered for our breast cancer survivors. More high-quality studies are needed to further elucidate the timing, duration, frequency and exercises for physical therapy in breast cancer.

\section{Advances in interventional procedures for breast cancer related pain}

Interventional options for management of pain are often a key component of a multimodal treatment plan, allowing the patients to fully participate in rehabilitation activities that are integral to a return to normal function. Unfortunately, there are limited high-quality studies assessing interventions for chronic pain after treatment for breast cancer. In fact, a recent systematic review found only seven high-quality studies assessing three targets: paravertebral blockade, stellate ganglion blockade and intercostal neural blockade [35]. However, there are exciting new interventional options being currently investigated on a preliminary basis.

Initially described by Blanco, the Pecs block and modified Pecs block, also known as the Pecs block type II, are two novel approaches to pain management for breast cancer. The anatomic target of these ultrasound-guided blocks is the interfacial plane between the pectoralis major muscle and the pectoralis minor muscle [36]. The modified Pecs block has an additional step of anesthetizing the space between the pectoralis minor muscle and the serratus anterior muscle [37]. Blanco's initial report of 50 patients undergoing surgery for breast cancer who received the Pecs block found that these women had minimal analgesic requirements in the post-surgical period [36]. A subsequent randomized controlled trial by Bashandy and Abbas found that pain scores were significantly lower in the post-operative period in women who underwent Pecs block type II prior to modified radical mastectomy for breast cancer. Additionally, analgesic usage was lower, and patients had shorter post-anesthesia care unit stays and overall hospitalization time [38]. A pilot study by Wijayasinghe et al. investigating the use of the Pecs block in eight patients with chronic pain after surgery for breast cancer demonstrated pain relief and reduced sleep interference for 7 days after the procedure, far beyond the expected duration of relief from local anesthetic alone [36]. These two approaches would be appropriate for women experiencing acute pain relating to breast cancer surgery, and chronic pain in the breast region post-surgery and possibly post-radiation therapy. Potential complications of these methods, and the methods discussed below, include bleeding, infection and damage to surrounding structures by the needle.

The serratus plane is another potential target for interventional management of pain related to breast cancer. There are two potential fascial planes surrounding the serratus anterior muscle on the chest wall, one superficial and one deep to the muscle. Injecting a local anesthetic into either plane under ultrasound guidance results in anesthesia of the hemithorax, likely secondary to targeting the intercostal nerves, although it is possible that the intercostobrachial nerve branches lie within this plane [39]. A recent case series found that utilization of the serratus plane block in conjunction with a Pecs block was effective in providing intra-operative and post-operative analgesia during surgery for breast reconstruction [40]. A recent retrospective study examined eight women who underwent this block with a local anesthetic and steroid, as treatment for chronic anterior chest wall pain relating to treatment for breast cancer. All women experienced initial pain relief after the block, and the duration of pain relief was variable, ranging from 2 to 3 days to 12 weeks, although some women still had pain relief at the time of the study's publication [41]. Further support for the use of the serratus anterior block as a treatment for chronic pain relating to treatment for breast cancer can be seen in a case report by Takimoto et al. utilizing a series of serratus plane blocks for a woman with chronic pain after surgery for breast cancer. Repeating these blocks allowed the woman to participate more readily in other modalities such as physical therapy and over time she improved to the point of no longer requiring interventional treatment [42]. 
The intercostobrachial nerve is an additional anatomic target for interventional treatments for pain related to breast cancer. The intercostobrachial nerve, which arises from the lateral cutaneous branch of the second intercostal nerve, is very vulnerable to damage during surgery for breast cancer, which can result in neuropathic pain. A pilot study conducted by Wijayasinghe et al. demonstrated that the second intercostal space was able to be consistently identified under ultrasound [43]. Since the intercostobrachial nerve reliably passes through this space, this allowed a target for an ultrasound-guided block of the intercostobrachial nerve. All of the six patients with chronic pain relating to treatment for breast cancer who underwent intercostobrachial nerve block had significantly reduced pain scores post-procedure, with one patient reporting pain relief at 3 months post-injection, despite only being treated with a local anesthetic [44]. Further investigation into this technique would be beneficial, including consideration of whether the addition of steroid might prolong the analgesic effects of this procedure.

Exploring all surgical options for the management of chronic pain relating to breast cancer is outside the scope of this review article; however, it is worth noting that Caviggioli et al. have had success with autologous fat grafting in painful mastectomy scars [45]. A more recent study by Maione et al. found similar improvement in pain scores with autologous fat grafting for women suffering from chronic pain after breast conservative surgery and radiotherapy, an increasingly popular method of surgical treatment for breast cancer [46].

Interventional management options for chronic pain relating to breast cancer are important because they often facilitate participation in rehabilitation treatments that are instrumental in allowing a return to function. They also often allow for a decrease in medication usage, which is often associated with undesirable side effects. These novel techniques may soon become common place in the treatment of the post mastectomy pain syndrome continuum.

\section{Conclusion}

Pain relating to breast cancer is a constellation of pain symptoms with numerous potential targets for treatment. Understanding the pathophysiology of the various etiologies may allow the pain practitioner to better direct a pain treatment plan for each individual patient. It is clear from our review that pain treatment begins at the start of the treatment for breast cancer, whether surgical or medical. Each breast cancer treatment chosen for a patient may lead to specific pain symptoms that should be diagnosed and treated. We advise that physical therapy and rehabilitation are the mainstay of treatment of these pain symptoms, while interventions may be used to alleviate pain symptoms during therapy.

Perhaps, further investigation is needed for pain symptoms that are chronic and not improving with conventional treatments mentioned above. Consideration for neuromodulation of neuropathic pain symptoms and regenerative medicine for musculoskeletal pain will be the next frontier for our patients. Regardless of the advances, it is clear that because of the complexity of breast cancer related pain, unique paradigms should be developed for each patient.

\section{Future perspective}

Clearly much work is still to be done to improve the treatment of pain relating to breast cancer. We feel that in the future treatments will be tailored to anatomic targets that are unique to a specific patient, taking into account the type of tumor and therapies the patient was subjected to. We also feel that there are exciting options in the areas of neuromodulation, both spinal cord stimulation and peripheral field stimulation. Other future considerations will include prolonging duration of pain relief from the blocks discussed above, including options such as radiofrequency ablation or chemoablation of certain targets.

\section{Financial \& competing interests disclosure}

The authors have no relevant affiliations or financial involvement with any organization or entity with a financial interest in or financial conflict with the subject matter or materials discussed in the manuscript. This includes employment, consultancies, honoraria, stock ownership or options, expert testimony, grants or patents received or pending, or royalties.

No writing assistance was utilized in the production of this manuscript.

Open access

This work is licensed under the Attribution-NonCommercial-NoDerivatives 4.0 Unported License. To view a copy of this license, visit http://creativecommons.org/licenses/by-nc-nd/4.0/ 


\section{References}

Papers of special note have been highlighted as: $\bullet$ of interest

1. Bethesda MD. SEER cancer statistics factsheets: female breast cancer. https://seer.cancer.gov/statfacts/html/breast.html

2. Glare PA, Davies PS, Finlay E et al. Pain in cancer survivors. J. Clin. Oncol. 32(16), 1739-1747 (2014).

3. Pachman DR, Barton DL, Swetz KM, Loprinzi CL. Troublesome symptoms in cancer survivors: fatigue, insomnia, neuropathy, and pain. J. Clin. Oncol. 30(30), 3687-3696 (2012).

4. Ewertz M, Jensen AB. Late effects of breast cancer treatment and potentials for rehabilitation. Acta Oncol. 50(2), 187-193 (2011).

5. Cheville AL, Troxel AB, Basford JR, Kornblith AB. Prevalence and treatment patterns of physical impairments in patients with metastatic breast cancer. J. Clin. Oncol. 26(16), 2621-2629 (2008).

6. Robb KA, Williams JE, Duvivier V, Newham DJ. A pain management program for chronic cancer-treatment-related pain: a preliminary study. J. Pain 7(2), 82-90 (2006).

7. Iyer S, Kim HJ. Cervical radiculopathy. Curr. Rev. Musculoskelet. Med. 9(3), 272-280 (2016).

8. Stubblefield MD, Keole N. Upper body pain and functional disorders in patients with breast cancer. PM R. 6(2), 170-183 (2014).

9. Crosbie J, Kilbreath SL, Dylke E et al. Effects of mastectomy on shoulder and spinal kinematics during bilateral upper-limb movement. Phys. Ther. 90(5), 679-692 (2010).

10. van Geel AN, Lans TE, Haen R, Tjong Joe Wai R, Menke-Pluijmers MBE. Partial mastectomy and M. Latissimus Dorsi reconstruction for radiation-induced fibrosis after breast-conserving cancer therapy. World J. Surg. 35(3), 568-572 (2011).

11. Torres Lacomba M, Mayoral del Moral O, Coperias Zazo JL, Gerwin RD, Goñí AZ. Incidence of myofascial pain syndrome in breast cancer surgery: a prospective study. Clin. J. Pain 26(4), 320-325 (2010).

12. McNeely ML, Campbell KL, Rowe BH, Klassen TP, Mackey JR, Courneya KS. Effects of exercise on breast cancer patients and survivors: a systematic review and meta-analysis. CMAJ 175(1), 34-41 (2006).

13. Cheville AL, Tchou J. Barriers to rehabilitation following surgery for primary breast cancer. J. Surg. Oncol. 95(5), 409-418 (2007).

14. Itoi E. Rotator cuff tear: physical examination and conservative treatment. J. Orthop. Sci. 18(2), 197-204 (2013).

15. De Groef A, Van Kampen M, Dieltjens E et al. Effectiveness of postoperative physical therapy for upper-limb impairments after breast cancer treatment: a systematic review. Arch. Phys. Med. Rehabil. 96(6), 1140-1153 (2015).

16. Halbert J, Crotty M, Cameron ID. Evidence for the optimal management of acute and chronic phantom pain: a systematic review. Clin. J. Pain. 18(2), 84-92 (2002).

17. Lotze M, Grodd W, Birbaumer N, Erb M, Huse E, Flor H. Does use of a myoelectric prosthesis prevent cortical reorganization and phantom limb pain? Nat. Neurosci. 2(6), 501-502 (1999).

18. Chan BL, Witt R, Charrow AP et al. Mirror therapy for phantom limb pain. N. Engl. J. Med. 357(21), 2206-2207 (2007).

19. Oerlemans MH, Oostendorp RAB, de Boo T, Goris JAR. Pain and reduced mobility in complex regional pain syndrome I: outcome of a prospective randomised controlled clinical trial of adjuvant physical therapy versus occupational therapy. Pain 83(1), 77-83 (1999).

20. Pachman DR, Barton DL, Watson JC, Loprinzi CL. Chemotherapy-induced peripheral neuropathy: prevention and treatment. Clin. Pharmacol. Ther. 90(3), 377-387 (2011).

21. Vadivelu N, Schreck M, Lopez J, Kodumudi G, Narayan D. Pain after mastectomy and breast reconstruction. Am. Surg. 74(4), 285-296 (2008).

22. Fourie WJ, Robb KA. Physiotherapy management of axillary web syndrome following breast cancer treatment: discussing the use of soft tissue techniques. Physiotherapy 95(4), 314-320 (2009).

23. Petit JY, Rietjens M, Ferreira MA, Montrucoli D, Lifrange E, Martinelli P. Abdominal sequelae after pedicled TRAM flap breast reconstruction. Plast. Reconstr. Surg. 99(3), 723-729 (1997).

24. Dell DD, Weaver C, Kozempel J, Barsevick A. Recovery after transverse rectus abdominis myocutaneous flap breast reconstruction surgery. Oncol. Nurs. Forum 35(2), 189-196 (2008).

25. Seber S, Solmaz D, Yetisyigit T. Antihormonal treatment associated musculoskeletal pain in women with breast cancer in the adjuvant setting. OncoTargets Ther. 9, 4929-4935 (2016).

26. Coleman RE, Bolten WW, Lansdown M et al. Aromatase inhibitor-induced arthralgia: clinical experience and treatment recommendations. Cancer Treat. Rev. 34(3), 275-282 (2008).

27. Peppone LJ, Janelsins MC, Kamen C et al. The effect of YOCAS ${ }^{\circledR}{ }^{\circledR}$ yoga for musculoskeletal symptoms among breast cancer survivors on hormonal therapy. Breast Cancer Res. Treat. 150(3), 597-604 (2015).

28. Irwin ML, Cartmel B, Gross CP et al. Randomized exercise trial of aromatase inhibitor-induced arthralgia in breast cancer survivors. J. Clin. Oncol. 33(10), 1104-1111 (2015).

29. Knols R, Aaronson NK, Uebelhart D, Fransen J, Aufdemkampe G. Physical exercise in cancer patients during and after medical treatment: a systematic review of randomized and controlled clinical trials. J. Clin. Oncol. 23(16), 3830-3842 (2005). 
30. Herrera JE, Stubblefield MD. Rotator cuff tendonitis in lymphedema: a retrospective case series. Arch. Phys. Med. Rehabil. 85(12), 1939-1942 (2004).

31. Ebaugh D, Spinelli B, Schmitz KH. Shoulder impairments and their association with symptomatic rotator cuff disease in breast cancer survivors. Med. Hypotheses 77(4), 481-487 (2011).

32. Korpan MI, Crevenna R, Fialka-Moser V. Lymphedema: a therapeutic approach in the treatment and rehabilitation of cancer patients. Am. J. Phys. Med. Rehabil. 90(5) (Suppl. 1), S69-S75 (2011).

33. De Groef A, Van Kampen M, Dieltjens E et al. Effectiveness of postoperative physical therapy for upper-limb impairments after breast cancer treatment: a systematic review. Arch. Phys. Med. Rehabil. 96(6), 1140-1153 (2015).

34. Beurskens CHG, van Uden CJT, Strobbe LJA, Oostendorp RAB, Wobbes T. The efficacy of physiotherapy upon shoulder function following axillary dissection in breast cancer, a randomized controlled study. BMC Cancer 7(1), 166 (2007).

35. Wijayasinghe N, Andersen KG, Kehlet H. Neural blockade for persistent pain after breast cancer surgery. Reg. Anesth. Pain Med. 39(4), 272-278 (2014).

36. Blanco R. The "pecs block": a novel technique for providing analgesia after breast surgery. Anaesthesia 66(9), 847-848 (2011).

- First description of this type of interventional block.

37. Blanco R, Fajardo M, Parras Maldonado T. Ultrasound description of Pecs II (modified Pecs I): a novel approach to breast surgery. Rev. Esp. Anestesiol. Reanim. 59(9), 470-475 (2012).

38. Bashandy A, Abbas D. Pectoral nerves I and II blocks in multimodal analgesia for breast cancer surgery: a randomized clinical trial. Reg. Anesth. Pain Med. 40(1), 68-74 (2015).

39. Wijayasinghe N, Andersen KG, Kehlet H. Analgesic and sensory effects of the pecs local anesthetic block in patients with persistent pain after breast cancer surgery: a pilot study. Pain Practice 17(2), 185-191 (2017).

40. Blanco R, Parras T, McDonnell JG, Prats-Galino A. Serratus plane block: a novel ultrasound guided thoracic wall nerve block. Anaesthesia 68, 1107-1113 (2013).

- Further development of Pecs block into a novel block, the serratus plane block.

41. Khemka R, Chakraborty A, Ahmed R, Datta T, Agarwal S. Ultrasound-guided serratus anterior plane block in breast reconstruction surgery. A. A. Case Rep. 6(9), 280-282 (2016).

42. Zocca JA, Chen GH, Puttanniah VG, Hung JC, Gulati A. Ultrasound-guided serratus plane block for treatment of postmastectomy pain syndromes in breast cancer patients: a case-series. Pain Pract. 17, 141-146 (2016).

43. Wijayasinghe N, Duriaud HM, Kehlet H, Andersen KG. Ultrasound-guided intercostobrachial nerve blockade in patients with persistent pain after breast cancer surgery: a pilot study. Pain Physician 19, E309-E316 (2016).

44. Takimoto K, Nishijima K, Ono M. Serratus plane block for persistent pain after partial mastectomy and axillary node dissection. Pain Physician 19, E481-E486 (2016).

45. Caviggioli F, Maione L, Forcellini D, Klinger F, Klinger M. Autologous fat graft in postmastectomy pain syndrome. Plast. Reconstr. Surg. 128(2), 349-352 (2011).

46. Maione L, Vinci V, Caviggioli F et al. Autologous fat graft in postmastectomy pain syndrome following breast conservative surgery and radiotherapy. Aesthetic Plast. Surg. 38(3), 528-532 (2014). 